\title{
GENE EXPRESSION OF ATP-SYNTHASE AS A PROGNOSTIC FACTOR IN PATIENTS WITH OVARIAN CANCER.
}

\section{Patrycja Ziober-Malinowska, Krzysztof Kułak, Marcin Bobiński, Jan Kotarski, Rafał Tarkowski}

I st Department of Gynaecological Oncology and Gynaecology, Medical University of Lublin, Poland

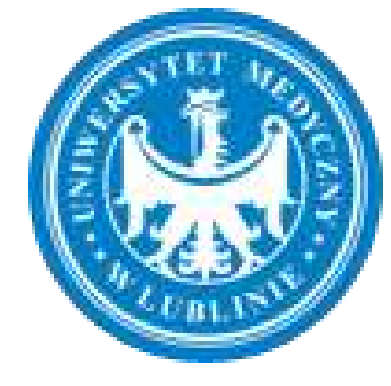

Medical University OF LUBLIN

\begin{abstract}
Introduction
Ovarian cancer $(\mathrm{OC})$ constitutes approx. $25 \%$ of female reproductive organs malignancies. $O C$ is usually diagnosed on higher levels of disease advancement. This fact effects with high morbidity of patiens. From this point of view it seems to be importnat to invent novel prognostic factor, other than clinical advancement and histological type. The aim of the study was to assess the relation of ATP-synthetase gene expression to patients overall survival and consequently its usefullness as a prognostic factor in OC.
\end{abstract}

\section{Material and methods}

The study was conducted in 48 women treated surgically for ovarian cancer between 2004 and 2008. Surgical treatment of patients studied was followed by chemotherapy (paclitaxel and cisplatin or carboplatin). The study group consist of women aged 22 - 78 years at diagnosis, the average age of patients with ovarian cancer was 53.8 years (26 - 82 years). The control group consist of 9 patients undergoing hysterectomy and salpingooopherectomy due to uterine fibroids from whom normal ovarian tissue was collected (average age 52.4 years (44 - 58)). Tissue samples were first examined histologically. RNA was isolated from harvested ovarian tissues, the assessments of its quality were performed.

ATP-synthetase gene expression was assessed with MACRO Array technique by comparing the normal tissue and tumor tissue. Gene expression was also analyzed depending on the survival of patients.
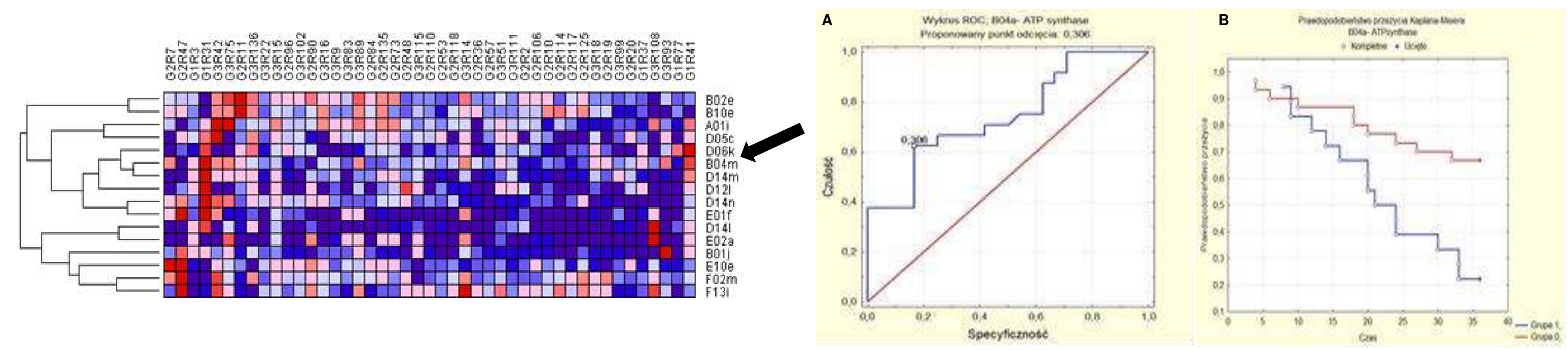

Fig.1. The „heat-map” of selected genes that differ between normal and cancer tissues (ATPsynthetasis gene is indicated by the arrow)

Fig.2. A. ROC curve of ATP-synthase gene expresion. B. The corelation between the ATPsynthase gene expresion and overall survival time. 0,306 cut-off point. Survival probability with Kaplan - Meier $(p=0,007)$

\section{Results}

Gene expression analysis showed that ATP-synthase present in the tumor tissue have differences in their expression compared to normal tissue. (Fig1.) ATP-synthase expression correlated with survival of patients with ovarian (ROC 0,306, p=0,007). (Fig.2)

Conclusion

Gene expression of ATP-synthase correlates with the overall survival of patients of ovarian cancer.

Further studies on mentioned gene and its products are required to asses its viability as biomarkers. 